\title{
A Dynamic Equilibrium Model of Real Exchange Rates with General Transaction Costs
}

\author{
GAUTAM GOSWAMI \\ Fordham University \\ MILIND SHRIKHANDE \\ Georgia State University \\ LIUREN WU \\ Fordham University
}

Follow this and additional works at: https://fordham.bepress.com/crif_working_papers

Part of the Finance and Financial Management Commons

\section{Recommended Citation}

GOSWAMI, GAUTAM; SHRIKHANDE, MILIND; and WU, LIUREN, "A Dynamic Equilibrium Model of Real Exchange Rates with General Transaction Costs" (2002). CRIF Working Paper series. 29.

https://fordham.bepress.com/crif_working_papers/29 


\title{
A Dynamic Equilibrium Model of Real Exchange Rates with General Transaction Costs*
}

\author{
GAUTAM GOSWAMI $^{\dagger}$ \\ Graduate School of Business, Fordham University \\ MILIND SHRIKHANDE ${ }^{\ddagger}$ \\ J. Mack Robinson College of Business, Georgia State University \\ LIUREN WU ${ }^{\S}$ \\ Graduate School of Business, Fordham University
}

March 12, 2002, first draft: February 21, 2001

\footnotetext{
*We thank Bernard Dumas, Cheol Eun, and David Nachman for helpful comments. Goswami acknowledges research support from Fordham University. We welcome comments, including references to related papers we inadvertently overlooked. The usual disclaimer applies. The latest version of the paper can be downloaded from http: //www. bnet. fordham. edu/l wu.

$\dagger 113$ West 60th Street, New York, NY 10023; tel: (212) 636-6181; fax: (212) 765-5573; goswami@fordham.edu.

$¥ 1221$ University Plaza, Atlanta, GA 30303; tel: (404) 651-2710; fax: (404) 651-2630; mshrikhande@gsu.edu.

$\S 113$ West 60th Street, New York, NY 10023; tel: (212) 636-6117; fax: (212) 765-5573; wu@ fordham. edu.
} 


\title{
A Dynamic Equilibrium Model of Real Exchange Rates with General Transaction Costs
}

\begin{abstract}
We study the behavior of real exchange rates in a two-country dynamic equilibrium model. In this model, consumers can only consume domestic goods but can invest costlessly in capital stocks of both countries. Nevertheless, transporting goods between the two countries is costly and, hence, the rebalancing of the capital stock can only happen finitely often. We propose a realistic cost structure for goods transportation, wherein the total cost increases with the amount of shipment but the unit cost decreases with it due to economies of scale. Given such a cost structure, the optimal decisions on when and how much to transfer need to be determined jointly. The dual decision depends upon the magnitude of economies of scale, the production technology specifications, and the consumer preferences. The model can reconcile the observed large short-term volatility of the real exchange rate with its slow convergence to parity. Further, the drift and diffusion of the real exchange rate are not uniquely determined by the real exchange rate level. The dynamics of the real exchange rate can only be determined by a joint analysis of the real exchange rate and the underlying economic fundamentals such as the capital stock imbalance between the two countries.
\end{abstract}

JEL Classification Codes: C51, F31, G12, G15.

Keywords: costs of goods transportation; economies of scale; real exchange rate; purchasing power parity; nonlinearity. 
A large body of literature has been devoted to the empirical studies of the real exchange rate and deviations from purchasing power parity (PPP). Among many inconclusive and often conflicting findings, researchers have come to a broad consensus on two main observations. First, the real exchange rate converges to purchasing power parity in the very long run, but the speed of convergence is extremely slow and nonlinear in the exchange rate level. Second, the short-run deviations from purchasing power parity are large and volatile. Reconciling the enormous short term volatility of the real exchange rate with its extremely slow convergence to parity represents a challenge to theoretical research. Rogoff (1996) provides an excellent review of this PPP puzzle and suggests that international goods markets remain quite segmented, with large trading frictions due to transportation costs, tariff and nontariff barriers, information costs, and labor immobility. Our paper reconciles the high short-term volatility of the real exchange rate with its extremely slow rate of decay to parity in a segmented international goods market with trading frictions due to transportation costs.

Dumas (1992) builds a pioneering general equilibrium model for real exchange rates with two countries and one good in a spatially separated world. The model endogenizes the nonlinear and slow mean-reverting behavior of the real exchange rate by introducing costs for goods transportation between the two production economies. The transportation cost results in a no-trade policy within a region of imbalance between the capital stocks in the two countries. In equilibrium, the real exchange rate deviates from parity and exhibits persistence at the boundaries of the region of imbalance. However, the analysis assumes that the transportation cost is purely proportional to the amount of shipment, ignoring any potential reduction in unit cost due to economies of scale. Such a cost structure leads to two major counterfactual implications. First, the optimal shipping amount is infinitesimal, regardless of production technology and consumer preference. Second, in equilibrium, the real exchange rate exhibits the largest volatility at parity, but the volatility declines monotonically and approaches zero as the deviation from parity increases. In reality, however, the optimal shipping quantity is always a finite amount, and the real exchange rate exhibits enormous short term volatility away from parity.

This article proposes a dynamic general equilibrium model of real exchange rates in an economy similar to Dumas (1992) but with a more general cost structure for goods transportation. In our model, the cost structure consists of two components. The first component is a proportional cost. Because of this component, the total cost increases with the shipping quantity. The second component generates 
decreasing unit cost of shipment with increasing shipping volume. It is a measure of the magnitude of economies of scale evident in most aspects of domestic and international trade. For example, economies of scale can arise from fixed nontradable input costs. In our model, the cost of the vessel for transporting goods is an example of such a nontradable input cost.

In the presence of economies of scale in goods transportation, the shipping strategy constitutes the dual decision: when to transfer goods and how much to transfer. We solve an intricate optimization problem which determines the optimal consumption stream and the optimal shipping strategy to maximize expected aggregate utility of consumption for consumers in the two countries. Inspired by Korn (1998), we first define a conditional optimization problem which determines the optimal shipping quantity conditional on immediate shipping. However, immediate shipping is not always optimal due to the presence of transportation cost. Immediate shipping is optimal when the value function defined by the conditional optimization problem coincides with the value function defined in the original optimization problem. We solve for optimal consumption and the optimal shipping strategy via an iterative procedure.

We find that introducing even a small degree of economies of scale in the cost structure significantly increases the optimal shipping quantity. Further, including economies of scale renders the optimal shipping strategy more sensitive to production technology and consumer preference. For example, a more volatile and less divergent production process lead consumers to tolerate a higher capital stock imbalance before they decide to transfer goods. On the other hand, an increase in consumers' relative risk aversion and time discounting results in lower tolerance for capital stock imbalance and hence more frequent capital stock rebalancing. Specifications on the production technology and consumer preference also affect the optimal shipping quantity decision in important ways. Overall, the optimal shipping quantity is determined by the increasing total cost and declining unit cost of goods transportation on the one hand and the benefits of risk sharing for the consumer on the other.

The dynamic behavior of real exchange rates is sensitive not only to the overall cost of goods transportation, but also to the specification of the cost structure. Increasing the overall cost of goods transportation slows down the speed of reversion of the real exchange rate to parity and increases its volatility. However, the persistence and volatility of the real exchange rate are much more sensitive to the economies of scale component than to the proportional cost component. In contrast to Dumas 
(1992) where the maximum volatility for the real exchange rate is at parity, we find that the largest exchange rate volatility can be realized at deviations from purchasing power parity, thus complying with the empirical evidence.

The presence of economies of scale results in finite goods transfer and hence generates jumps in the dynamic process for capital stock imbalance. Yet, in equilibrium, the real exchange rates before and after each jump in the capital stock must remain the same to exclude arbitrage. The interesting consequence is that two different levels of capital stock imbalance correspond to the same level of real exchange rate. While each capital imbalance level uniquely determines a real exchange rate level, the opposite is not always true. One cannot always infer the capital imbalance from the real exchange rate level. This loss of one-to-one mapping also generates indeterminacy in the drift and diffusion functions of the real exchange rate dynamics. At a given real exchange rate level, both the drift (mean-reverting force) and the diffusion (instantaneous volatility) of the exchange rate can take either of two values, determined by the capital imbalance at that instant in time.

The indeterminacy in real exchange rate dynamics has important implications for empirical research. Time series analysis of the real exchange rate data alone is not enough to fully reveal the exchange rate dynamics. Such data need to be complemented with time series data on economic fundamentals such as trade imbalance or capital flows. Dumas (1992) argues that a linear specification in estimating the real exchange rate dynamics is severely misspecified and hence may lead to erroneous conclusions. His modeling effort has motivated several empirical studies to explore nonlinear specifications in testing the mean-reverting behavior of the real exchange rates, e.g. Baum, Barkoulas, and Caglayan (2001), Lothian and Taylor (1996), Michael, Nobay, and Peel (1997), Sarantis (1999), and Taylor and Peel (2000). Our model results further indicate that, in the presence of economies of scale in the transportation cost, an exogenous time series analysis of the real exchange rate data alone may still lead to erroneous conclusions even if one considers nonlinearity and/or heteroskedasticity. The key issue is that the drift and diffusion functions of the real exchange rates are not completely determined by the real exchange rate levels. Our model argues for joint analysis of exchange rates and economic fundamentals.

Our model builds directly on the dynamic real exchange rate equilibrium model in Dumas (1992). The model framework in Uppal (1993), Hollifield and Uppal (1997), and Dumas and Uppal (2001)) 
are also similar, except that they, like in Dumas (1992), all assume a purely proportional type of cost structure. There is also a parallel strand of literature based on purely fixed or purely proportional transaction costs in optimal portfolio selection. Examples include Atkinson and Wilmott (1995), Constantinides (1986), Cuoco and Liu (2000), Cvitanić (1996), Eastham and Hastings (1988), Davis and Norman (1990), Duffie and Sun (1990), Dumas and Luciano (1991), Grossman and Laroque (1990), Korn (1998), Liu (2001), Liu and Loewenstein (2001), Lo, Mamaysky, and Wang (2000), Morton and Pliska (1995), Oksendal and Sulem (1999), Shreve and Soner (1994), Vayanos (1998), and Schroder (1995, 1997).

While our model focuses on the real economy, monetary models have also been proposed in the literature to explain real exchange rate behavior. For example, the overshooting model of Dornbusch (1976) attributes the short term deviations from purchasing power parity to stickiness in nominal prices. Other explanations of the short term exchange rate volatility in monetary models include financial factors such as changes in portfolio preferences, short-term asset price bubbles, and monetary shocks (Obstfeld and Rogoff 1995), but such models cannot generate the observed slow convergence to PPP. On the other hand, as Rogoff (1996) points out, real models can readily explain the slow adjustment of real exchange rate to parity. Nevertheless, earlier real models such as Dumas (1992) cannot account for the high short-term real exchange rate volatility. Our general cost structure not only renders the real exchange rate more volatile, but also generates the observed persistence in real exchange rates.

Furthermore, a valid explanation of short-term exchange rate volatility cannot rely too heavily on non-traded goods or institutional factors such as exchange rate regimes because the evidence on high volatility for PPP deviations even among highly traded goods is remarkably stable over the past 700 years (Froot, Kim, and Rogoff 1995). Our model focuses on the real economy and hence does not rely on any institutional or monetary factors. Nevertheless, the model successfully explains both the short term real exchange rate volatility and its slow decay to parity via a general specification of the cost structure for goods transportation.

The structure of the paper is as follows. The next section sets up the model and delineates the procedure for solving the general equilibrium in the presence of a general cost structure. Section II analyzes the optimal shipping decisions, both when and how much to ship, as a function of the cost structure, the production technology, and the consumer preference. Section III analyzes the optimal 
consumption decision and the physical imbalance dynamics. Section IV investigates the real exchange rate dynamics under such a model. Section V concludes.

\section{A Dynamic Equilibrium Model with Transaction Costs}

The model structure follows Dumas (1992). It consists of two countries (home and foreign) with identical consumers who can own and trade a single type of consumption good. Consumers can only consume goods within their own country, but can invest in a constant-return-to-scale production process for goods in either country. The capital stocks of goods at time $t$ are $K_{t}$ and $K_{t}^{*}$ at home and abroad, respectively. Goods transportation is costly and hence goods can only be transported for a finite number of times within any finite time intervals. During quiescent periods absent of goods shipment, the dynamics of the capital stocks are governed by the following stochastic differential equations:

$$
\begin{aligned}
d K_{t} & =\left(\kappa K_{t}-c_{t}\right) d t+\sigma K_{t} d z_{t} \\
d K_{t}^{*} & =\left(\kappa K_{t}^{*}-c_{t}^{*}\right) d t+\sigma K_{t}^{*} d z_{t}^{*}
\end{aligned}
$$

where $\left(c, c^{*}\right)$ are domestic and foreign rates of consumption and $\left(d z, d z^{*}\right)$ denote independent Wiener processes which proxy for production shocks in each country.

\section{A. The Cost Structure}

The key innovation of our model is in the specification of the cost structure for goods transportation. Dumas (1992) assumes that the transportation cost is purely proportional. In case of $K>K^{*}$, let $X>0$ denote the amount of the shipment from the home country to the foreign country, the foreign country only receives a constant proportion of the shipment, $s X$, with $s \in[0,1] .{ }^{1}$ Such an assumption completely ignores any potential economies of scale. The unit cost does not decline with increasing shipment. It leads to a counterfactual implication that the optimal amount of shipment is infinitesimal. In reality, however, while the total cost increases with the amount of shipment, the unit cost often decreases due

\footnotetext{
${ }^{1}$ The shipment from the foreign country to the home country, $X^{*}$, is determined analogously by symmetry. Throughout the paper, we focus on the case when $K>K^{*}$ and derive the case of $K<K^{*}$ by symmetry.
} 
to economies of scale. To capture both effects, we let the unit cost be a positive, but decreasing function of the fraction of capital stock transferred. Specifically, we assume that the unit cost, $\theta$, is inversely proportional to the fraction of the capital stock transferred:

$$
\theta(\xi)=\alpha+\beta / \xi, \quad \alpha, \beta \in[0,1]
$$

where the parameter $\alpha$ denotes the constant, or proportional part of the cost, the parameter $\beta$ measures the magnitude of economies of scale, and the percentage transfer $\xi$ is defined as

$$
\xi \equiv X / X_{\max }
$$

where $X_{\max }$ denotes the maximum possible amount of goods transfer. We label $\alpha$ as the coefficient of proportional cost and $\beta$ as the coefficient of economies of scale. Under such a structure, while the total cost increases with the amount of shipment, the unit cost decreases. The structure captures the most frequently observed feature of transportation cost. The inverse proportionality presents a tractable way to capture the economies of scale. ${ }^{2}$ The parameter restrictions follow from the requirement that the total loss in transit cannot exceed the maximal amount of shipment.

We further argue that, irrespective of the cost structure, the home country consumers do not have the incentive to transfer more than the capital stock imbalance, $X_{\max }=K-K^{*}$. Refer to Appendix A for a proof. Thus, given a shipment of $X$ from home to abroad, the capital stock of the home country reduces to $K-X$ while the capital stock of the foreign country increases to

$$
K^{*}+(1-\theta(\xi)) X=(1+\beta) K^{*}+(1-\alpha) X-\beta K
$$

\section{B. The Central Planning Problem}

The economy, by assumption, is such that consumers can achieve a Pareto-optimal allocation of consumption. Under such an assumption, the capital market and goods market equilibrium can be repli-

\footnotetext{
${ }^{2}$ Dumas (1992)'s pure proportional cost case can be regarded as a special case of our cost structure with $\beta=0$ and $s=1-\alpha$.
} 
cated by a central planning problem. The welfare function is constructed as an equally weighted average of the individual lifetime utility functions. The equal weight is a result of our assumption of strict symmetry between the two countries, including their respective initial endowments. Implicit prices, which would prevail explicitly in decentralized markets, can then be obtained from the derivatives of the indirect utility function.

Consumers of both countries have the incentive to bring the two countries' stock of goods to balance for reasons of risk-sharing. Nevertheless, in the presence of a transportation cost, goods shipment between the two countries can only happen finite number of times within any finite time interval. Stock imbalance can persist for a long period of time. Thus, the central planner's decision is twofold: the optimal consumption plan for both home and foreign consumers and the optimal shipping decision. Let $c\left(K, K^{*}\right)$ and $c^{*}\left(K, K^{*}\right)$ denote the consumption flow at home and abroad as a function of the capital stock. Let $\Omega\left(K, K^{*}\right)$ denote an admissible shipping strategy, which potentially includes both decisions, when the shipping should occur and how much should be shipped. The central planning problem is to reach optimal consumption and shipment decisions to maximize the expected utility of aggregate consumption:

$$
V\left(K, K^{*}\right) \equiv \max _{c, c^{*}, \Omega} \mathbb{E}_{t} \int_{t}^{\infty} e^{-\rho(u-t)}\left[\frac{1}{\gamma} c_{u}^{\gamma}+\frac{1}{\gamma}\left(c_{u}^{*}\right)^{\gamma}\right] d u
$$

subject to the stock dynamics in (1) in the absence of shipment and subject to the cost structure in (2) when shipping takes place. In (3), $\rho \in \mathbb{R}^{+}$represents the time discount factor and $(1-\gamma)$ captures the relative risk aversion with $\gamma<1$. The instantaneous utility of consumption is identical for consumers of both countries and takes the form of constant relative risk averse utility (CRRA):

$$
u(c, t)=\frac{1}{\gamma} c_{t}^{\gamma}, \quad u\left(c^{*}, t\right)=\frac{1}{\gamma}\left(c_{t}^{*}\right)^{\gamma}
$$

The CRRA utility, together with our assumption on the cost structure guarantees that the solution for the indirect utility function $V\left(K, K^{*}\right)$ is homogeneous of degree $\gamma$. Furthermore, if $X$ is the optimal amount of shipment from home to abroad for initial conditions $\left(K, K^{*}\right)$, then $2 X$ is the optimal shipment for initial conditions $\left(2 K, 2 K^{*}\right)$. The same homogeneity applies to the shipment from abroad to home, $X^{*}$. 


\section{The Solution}

When the transportation cost is purely proportional, Dumas (1992) suggests that the optimal amount of shipment is infinitesimal whenever it is optimal to make a shipment. The optimal shipping strategy involves only the decision on when to make the infinitesimal shipment. Furthermore, due to the homogeneity and symmetric nature of the problem, Dumas (1992) contends that the optimal shipping decision is governed by a cone defined by two symmetric boundaries on the ratio of the home and foreign stock of capital, $K / K^{*} \in\left[\lambda_{1}, 1 / \lambda_{1}\right], \lambda_{1}>1$. No shipment occurs as long as the ratio $K / K^{*}$ is within this boundary. The amount of the shipment at the boundary is infinitesimal.

In the presence of economies of scale, an infinitesimal shipment is no longer optimal. We use $X$, the shipping amount from home to abroad, or $\xi$, the percentage transferred, to denote the optimal decision on shipping quantity. A finite shipment moves the capital stock imbalance strictly inside the original boundary. Analogous to the optimal shipping boundary, there also exists an ex-shipping boundary $\left[\lambda_{2}, 1 / \lambda_{2}\right]$, which defines the position immediately after the shipment. The new imbalance $\lambda_{2}$ is determined by the shipping boundary $\lambda_{1}$, the optimal shipping percentage $\xi$, and the cost of the shipment. In particular, they are linked by

$$
\lambda_{2}=\frac{\lambda_{1}-\xi\left(\lambda_{1}-1\right)}{(1+\beta)+(1-\alpha) \xi\left(\lambda_{1}-1\right)-\beta \lambda_{1}} .
$$

Thus, the optimal shipping decision can now be written as a bivariate decision: $\left\{\lambda_{1}, \xi\right\}$, where $\lambda_{1}$ determines when to ship and $\xi$ determines how much.

To determine the optimal shipping amount, $X$, we introduce the following maximum operator:

$$
M V\left(K, K^{*}\right) \equiv \max _{X} V\left(K-X,(1+\beta) K^{*}+(1-\alpha) X-\beta K\right)+\frac{1}{\gamma}\left(c_{t}^{\gamma}+\left(c_{t}^{*}\right)^{\gamma}\right)
$$

when $K>K^{*}$. The case of $K<K^{*}$ is determined by symmetry. Note that $M V\left(K, K^{*}\right)$ represents the value of the strategy that consists of taking the best immediate action. Since it is not always optimal to act immediately, we have

$$
V\left(K, K^{*}\right) \geq M V\left(K, K^{*}\right)
$$


Conceptually, we can now separate the optimization problem in (3) into two parts:

1. Within the no-shipping range of $K / K^{*} \in\left[\lambda_{1}, 1 / \lambda_{1}\right]$, the optimal consumption decision $\left(c, c^{*}\right)$ is solved based on the standard Bellman-Hamilton-Jacob equation, e.g. Merton (1971),

$$
0=\left[\frac{1}{\gamma} c_{t}^{\gamma}+\frac{1}{\gamma}\left(c_{t}^{*}\right)^{\gamma}\right]+\mathcal{L} V
$$

where $\mathcal{L} V$ denotes the infinitesimal generator of $V$ :

$$
\begin{aligned}
\mathcal{L} V= & -\rho V+V_{1}\left(\kappa K_{t}-c_{t}\right)+V_{2}\left(\kappa K_{t}^{*}-c_{t}^{*}\right) \\
& +\frac{1}{2} V_{11} \sigma^{2} K^{2}+\frac{1}{2} V_{22} \sigma^{2} K^{* 2},
\end{aligned}
$$

where $V_{i}$ is the partial derivative of the value function $V\left(K, K^{*}\right)$ with respect to its $i$ th argument, $i=K, K^{*}$, and $V_{i j}$ denotes the second partial derivative.

2. When it is optimal to ship at the boundary $K / K^{*}=\lambda_{1}$, the problem in (4) converges to optimal problem in (3):

$$
M V\left(K, K^{*}\right)=V\left(K, K^{*}\right), \quad \text { at } \quad K / K^{*}=\lambda_{1}
$$

The optimal shipping percentage, $\xi$, can then be determined by the optimization problem in (4).

\section{C.1. The Evolution of the Value Function}

Within the no-shipping zone, from the Bellman-Hamilton-Jacob equation in (5), the first order conditions with respect to optimal consumption are

$$
0=c_{t}^{\gamma-1}-V_{1} ; \quad 0=\left(c_{t}^{*}\right)^{\gamma-1}-V_{2},
$$

from which we obtain the optimal consumptions as a function of the indirect utility function:

$$
c_{t}=V_{1}^{\frac{1}{\gamma-1}}, \quad c_{t}^{*}=V_{2}^{\frac{1}{\gamma-1}} .
$$


Plug in the optimal consumption decisions back to equation (5), we obtain the following partial differential equation:

$$
\begin{aligned}
0= & \left(\frac{1}{\gamma}-1\right)\left(V_{1}^{\frac{\gamma}{\gamma-1}}+V_{2}^{\frac{\gamma}{\gamma-1}}\right) \\
& -\rho V+V_{1} \kappa K+V_{2} \kappa K^{*}+\frac{1}{2} V_{11} \sigma^{2} K^{2}+\frac{1}{2} V_{22} \sigma^{2} K^{* 2} .
\end{aligned}
$$

This partial differential equation governs the evolution of the value function. The value function can be solved given boundary conditions derived in the following subsection.

\section{C.2. The Optimal Shipping Decision}

In the presence of a general cost structure as in (2), the optimal shipping decision includes both the optimal shipping time and the optimal shipping quantity. Due to the homogeneity of our setup, the two decisions can be represented by the two boundaries: $\left\{\lambda_{1}, \lambda_{2}\right\}$, the physical imbalance of the capital stock between home and abroad before and after the shipment. The two boundaries are determined by the following four conditions: (1) symmetry, (2) value matching, (3) smooth pasting, and (4) optimal shipping.

Symmetry: Since the two countries are strictly symmetric, we expect that consumers in the two countries have the same marginal utility when the capital stock is at balance $\left(K=K^{*}\right)$ :

$$
V_{1}\left(K, K^{*}\right)=V_{2}\left(K, K^{*}\right) \quad \text { at } \quad K=K^{*}
$$

Value matching: The value function $V\left(K, K^{*}\right)$ before and after shipment should be identical:

$$
V\left(K, K^{*}\right)=V\left(K-X,(1+\beta) K^{*}+(1-\alpha) X-\beta K\right) \quad \text { at } \quad K / K^{*}=\lambda_{1} .
$$

Smooth pasting: The marginal utility before and after shipping should also match each other:

$$
V_{i}\left(K, K^{*}\right)=V_{i}\left(K-X,(1+\beta) K^{*}+(1-\alpha) X-\beta K\right) \quad \text { at } \quad K / K^{*}=\lambda_{1},
$$


for $i=1,2$.

Optimal shipment: At the boundary $K / K^{*}=\lambda_{1}$, the optimal shipment is determined by the optimization problem in (4):

$$
M V\left(K, K^{*}\right) \equiv \max _{X} V\left(K-X,(1+\beta) K^{*}+(1-\alpha) X-\beta K\right)+\frac{1}{\gamma}\left(c_{t}^{\gamma}+\left(c_{t}^{*}\right)^{\gamma}\right)
$$

Optimal consumption in (7) right before shipping implies

$$
\begin{aligned}
c_{t} & =V_{1}\left(K, K^{*}\right)=V_{1}\left(K-X,(1+\beta) K^{*}+(1-\alpha) X-\beta K\right), \\
c_{t}^{*} & =V_{2}\left(K, K^{*}\right)=V_{2}\left(K-X,(1+\beta) K^{*}+(1-\alpha) X-\beta K\right),
\end{aligned}
$$

The two equalities above for both $c_{t}$ and $c_{t}^{*}$ are the result of imposing the smooth pasting conditions. We hence have

$$
M V\left(K, K^{*}\right)=\max _{X}\left[V+\frac{1}{\gamma}\left(V_{1}^{\frac{\gamma}{\gamma-1}}+V_{2}^{\frac{\gamma}{\gamma-1}}\right)\right],
$$

where the indirect value function $V$ and its derivatives are all evaluated at the after-shipping position: $\left(K-X,(1+\beta) K^{*}+(1-\alpha) X-\beta K\right)$. The first order condition with respect to $X$ is given by

$$
\begin{aligned}
0= & -\left[V_{1}+\frac{1}{\gamma-1}\left(V_{1}^{\frac{1}{\gamma-1}} V_{11}+V_{2}^{\frac{1}{\gamma-1}} V_{21}\right)\right] \\
& +(1-\alpha)\left[V_{2}+\frac{1}{\gamma-1}\left(V_{1}^{\frac{1}{\gamma-1}} V_{12}+V_{2}^{\frac{1}{\gamma-1}} V_{22}\right)\right] .
\end{aligned}
$$

In principle, the value functions and the boundaries can be solved from the partial differential equation in (8) and the four boundary conditions: (9), (10), (11), and (12). However, trying to directly solve the problem from the above conditions is a daunting numerical task.

In what follows, we take advantage of the homogeneity and symmetry of the problem and solve the problem via some change of variables. 


\section{C.3. Solving the Boundaries and Value Function via Transformation}

Recognizing the homogeneity of the value function and the optimal shipment decision, we perform the following change of variables, ${ }^{3}$

$$
\omega \equiv \ln K / K^{*}, \quad I(\omega) \equiv-\gamma \ln K^{*}+\ln \|V\|, \quad I(-\omega) \equiv-\gamma \ln K+\ln \|V\|,
$$

where $\omega$ defines the logarithm of the stock imbalance ratio and $I(\omega)$ defines a transformed value function at such an imbalance. Under such transformation, the partial differential equation in (8) can be transformed into a second order ordinary differential equation in terms of $I(\omega)$ :

$$
I^{\prime \prime}(\omega)=-\left(I^{\prime}(\omega)\right)^{2}+\gamma I^{\prime}(\omega)+\frac{1}{\sigma^{2} \eta} e^{(\eta-1) I(\omega)}\left(I^{\prime}(\omega) \zeta_{1}(\omega)+\left(\gamma-I^{\prime}(\omega)\right) \zeta_{2}(\omega)\right)+\delta
$$

where

$$
\begin{aligned}
\eta & =\frac{\gamma}{\gamma-1}, \quad \delta=\frac{\rho-\alpha \gamma}{\sigma^{2}}-\frac{1}{2}\left(\gamma^{2}-\gamma\right) . \\
\zeta_{1}(\omega) & =\left\|I^{\prime}(\omega)\right\|^{\eta-1} e^{-\omega \eta}, \quad \zeta_{2}(\omega)=\left\|\gamma-I^{\prime}(\omega)\right\|^{\eta-1} .
\end{aligned}
$$

The symmetry condition in (9) implies,

$$
I^{\prime}(0)=\gamma / 2
$$

From the value matching condition in (10), we can obtain the following link between $I\left(\omega_{1}\right)$ and $I\left(\omega_{2}\right)$ :

$$
I\left(\omega_{1}\right)=I\left(\omega_{2}\right)+\gamma \ln \frac{1+\beta+\lambda_{1}(1-\alpha-\beta)}{1+(1-\alpha) \lambda_{2}}
$$

\footnotetext{
${ }^{3}$ A similar change of variables is applied in Dumas (1992). We modify his specification by applying the logarithm on the mode (absolute value) of $V$ rather than on $V$ directly. This allows us to consider the cases where the risk aversion is higher than the $\log$ utility, that is, $\gamma<0$.
} 
where $\left(\omega_{1}, \omega_{2}\right)$ are the logarithms of $\left(\lambda_{1}, \lambda_{2}\right)$. The smooth pasting conditions in (11), on the other hand, yield the solutions for $I^{\prime}(\omega)$ at the two boundaries $\omega_{1}$ and $\omega_{2}$ :

$$
\begin{aligned}
& I^{\prime}\left(\omega_{1}\right)=\gamma \lambda_{1}\left(\frac{1-\alpha-\beta\left(\lambda_{1}-1\right) /\left(\lambda_{1}-\lambda_{2}\right)}{1+\beta+(1-\alpha-\beta) \lambda_{1}}\right), \\
& I^{\prime}\left(\omega_{2}\right)=\gamma \lambda_{2}\left(\frac{1-\alpha-\beta\left(\lambda_{1}-1\right) /\left(\lambda_{1}-\lambda_{2}\right)}{1+(1-\alpha) \lambda_{2}}\right) .
\end{aligned}
$$

Finally, the first order condition on the optimal shipping in (12) can be used, together with the second order differential equation in (14), to derive the second order derivative of the value function $I^{\prime \prime}(\omega)$ at $\omega_{2}$ :

$$
I^{\prime \prime}\left(\omega_{2}\right)=\frac{-B+\sqrt{B^{2}-4 A C}}{2 A},
$$

where $A, B, C$ are functions of $\omega_{2}, I^{\prime}\left(\omega_{2}\right)$, and model parameters. The derivation of (19) as well as the specifications for $A, B, C$ are given in Appendix B.

The boundaries and the transformed value functions $I(\omega)$ at all $\omega \in\left[-\omega_{1}, \omega_{1}\right]$ can be solved through a shooting approach. We start with a guess of the pair $\left(\omega_{1}, \omega_{2}\right)$. We then solve for $I^{\prime}\left(\omega_{2}\right)$ from (18) and then $I^{\prime \prime}\left(\omega_{2}\right)$ through (19). The transformed value function $I\left(\omega_{2}\right)$ can then be derived from the ordinary differential equation in (14). Given the transformed value function $I(\omega)$ and its derivatives at $\omega_{2}$, we numerically run through the ordinary differential equation to generate the value functions and its derivatives at all other $\omega$ 's. The optimal boundaries $\left(\omega_{1}, \omega_{2}\right)$ are obtained by matching the marginal value functions $I^{\prime}(0)$ and $I^{\prime}\left(\omega_{2}\right)$ implied from the ordinary differential equation with those computed from the symmetry condition in (15) and the smooth pasting condition in (18). The ordinary differential equation can be solved using standard numerical procedure such as the fourth order RungeKutta method.

\section{Limiting Case}

Recall that the unit cost of goods transportation is assumed to be positive but inversely proportional to the percentage amount transferred:

$$
\theta(\xi)=\alpha+\beta / \xi
$$


It captures both the effect of increasing cost with increasing shipment and the idea of decreasing unit cost due to economies of scale. By setting the coefficient of economies of scale, $\beta$, to zero, the cost structure degenerates into the purely proportional cost case of Dumas (1992). In that case, it is optimal to ship only an infinitesimal amount each time. The capital stock imbalance before and after the shipment remains the same (only differs infinitesimally): $\lambda_{1}=\lambda_{2}=\lambda$. Therefore, one only needs to determine one boundary and does not need to solve the optimal shipment condition in (12). Refer to Dumas (1992) for details.

\section{Optimal Shipping Policy}

Given model parameters, we can solve the model numerically to obtain the optimal shipping decisions $\left\{\lambda_{1}, \xi\right\}$ and the transformed value functions. In this section, we investigate the impact of different model parameters on the optimal shipping decision. Since a nontrivial optimal shipping decision is a direct result of the presence of shipping cost, we start with the most important parameters for the optimal shipping, $(\alpha, \beta)$, that govern the cost structure for goods transportation. We analyze how the cost structure changes the decisions on when and how much to ship. We then proceed to analyze the impact of the production parameters and consumer preference parameters on the optimal shipping decision, both under the purely proportional cost structure of Dumas (1992) as well as under our general cost structure.

\section{A. Impact of the Cost Structure}

Recall that the unit cost of shipment is specified as $\theta(\xi)=\alpha+\beta / \xi$, where $\xi$ denotes the percentage shipment, $\alpha$ is the coefficient of proportional cost and $\beta$ is the coefficient of economies of scale. The bigger $\alpha$ is, the faster the total cost increases proportional to the amount of shipment. On the other hand, the bigger $\beta$ is, the larger the economies of scale, and hence the faster the unit cost reduces with shipping quantity. Figure 1 depicts the impact of the cost structure $(\alpha, \beta)$ on the optimal shipping decisions. The left panel depicts the impact on the optimal timing of the shipment, which is captured by the outer boundary $\lambda_{1}$ of the capital stock imbalance. The right panel depicts the impact on the optimal fraction of shipment. 

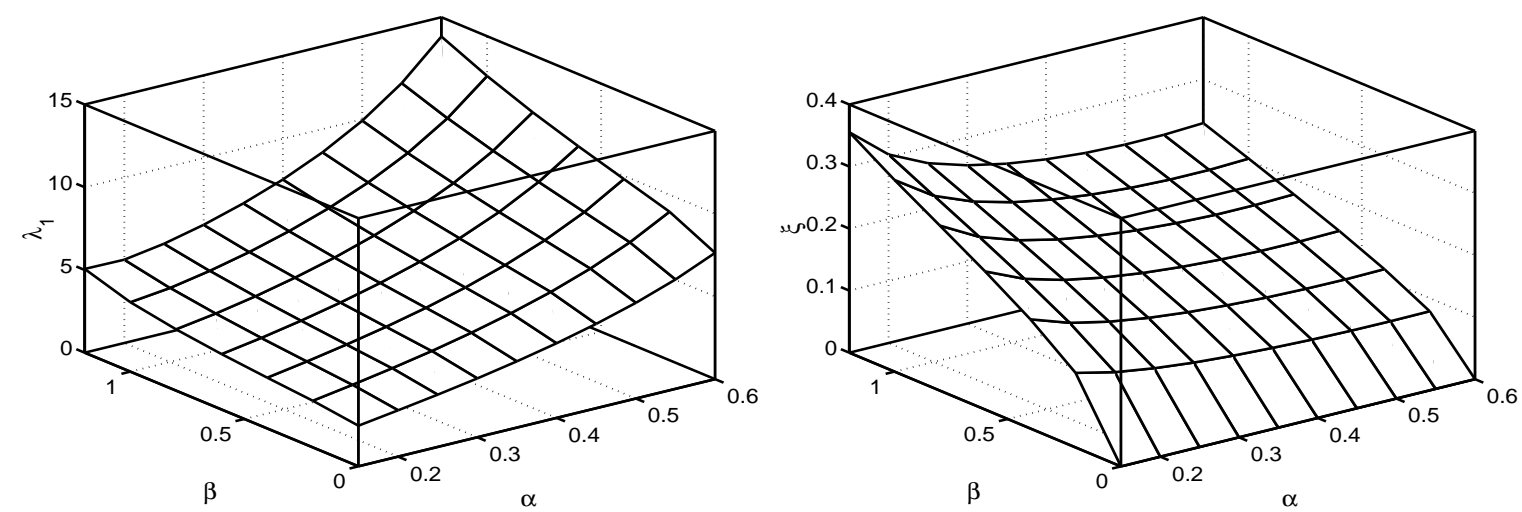

Figure 1: Impact of Cost Structure on Optimal Shipping Decision

The surface in the left panel depicts the optimal shipping boundary, denoted by $\lambda_{1}$, while the surface in the right panel depicts the optimal fraction of shipping quantity $\xi$. Both are plotted against the constant cost coefficient $\alpha$ and the coefficient of economies of scale $\beta$. The units of $\beta$ is scaled up by $10^{3}$. Other parameters are: $\kappa=0.11, \sigma=0.5, \gamma=-1, \rho=0.15$.

The left panel indicates that $\lambda_{1}$ increases with both coefficients $\alpha$ and $\beta$. As both coefficients $\alpha$ and $\beta$ increase, the boundary $\lambda_{1}$, at which shipping occurs, increases. As expected, as the cost increases, regardless of its nature, it is optimal for the consumers to tolerate a larger capital imbalance before a shipment.

The optimal percentage shipment, $\xi$, however, is very sensitive to the specific nature of the cost, as shown in the right panel of Figure 1. The optimal shipping quantity increases dramatically with increasing economies of scale $(\beta)$. Intuitively, the larger $\beta$ is, the more cost reduction is achieved through shipping a larger amount. Hence, the unit cost reduction requires an increase in the optimal shipping quantity. In absence of economies of scale $(\beta=0)$, the unit cost remains the same no matter how much is shipped. Thus, it is optimal to ship an infinitesimal amount at each time of shipment, as is the case in Dumas (1992). But, an infinitesimal amount of shipment is never going to be optimal in the presence of even a very small economies of scale factor. Note that, in the plots, the magnitude of $\beta$ is very small (scaled up by $10^{3}$ ), yet its impact on the optimal shipping amount is very significant.

While increasing economies of scale $(\beta)$ increases the optimal quantity of shipment rapidly, increasing the coefficient of proportional cost $(\alpha)$ actually reduces the optimal amount of shipment. Holding $\beta$ constant, increasing $\alpha$ amounts to an increase in the proportional cost and a relative reduction in the economies of scale component. 
Comparing the two panels in Figure 1 indicates that the two components of the cost structure play almost separate roles in the optimal shipping decision. While decision on the shipping boundary $\left(\lambda_{1}\right)$ is mainly controlled by the magnitude of the proportional cost, the decision on the optimal shipping quantity is dominated by the economies of scale component.

\section{B. Impact of Production Technology}

In addition to optimal consumption and shipping decisions, the capital stocks of the two countries fluctuate over time due to production shocks. The fluctuation is controlled by two parameters: $\sigma$ and $\kappa$. The diffusion parameter $\sigma$ determines the instantaneous impact of a production shock. The larger $\sigma$ is, the larger the impact of the production shock. The drift parameter $\kappa$, on the other hand, controls the serial dependence of the capital stock. A negative $\kappa$ is an indication of mean reversion while a positive $\kappa$ is an indication of diversion. The more positive $\kappa$ is, the faster the capital stock drifts away from its current position.

In making the optimal shipping decision, consumers are not only concerned with the cost of shipping, but also concerned with the dynamics of production shocks. For example, if one expects the capital stock will soon come back to balance by itself, one may want to wait for the natural balancing event instead of incurring a cost in making a shipment. On the other hand, if one expects the capital stock imbalance to increase further in the future, one may want to intervene early to stop that trend. Such considerations affect not only when to ship, but also how much to ship. Figure 2 depicts the impact of the two production parameters $\sigma$ and $\kappa$ on the optimal shipping decision. Again, the left panels depict the impact on $\lambda_{1}$, which captures when to ship, and the right panels depict the impact on $\xi$, the optimal fraction of shipment. The solid lines depict a general cost structure with both a constant proportion $(\alpha=0.18)$ and modest economies of scale $(\beta=0.001)$. The dashed lines depict the purely proportional case with zero economies of scale $(\beta=0)$. For ease of comparison, the parameters are chosen to match those in Dumas (1992). The dashed lines, thus, represent a replication of Dumas (1992)'s results.

The left panel in Figure 2 indicates that the direction of the impact of the production technology on the optimal boundary $\lambda_{1}$ remains the same with different cost structures. Nevertheless, the boundary $\lambda_{1}$ 

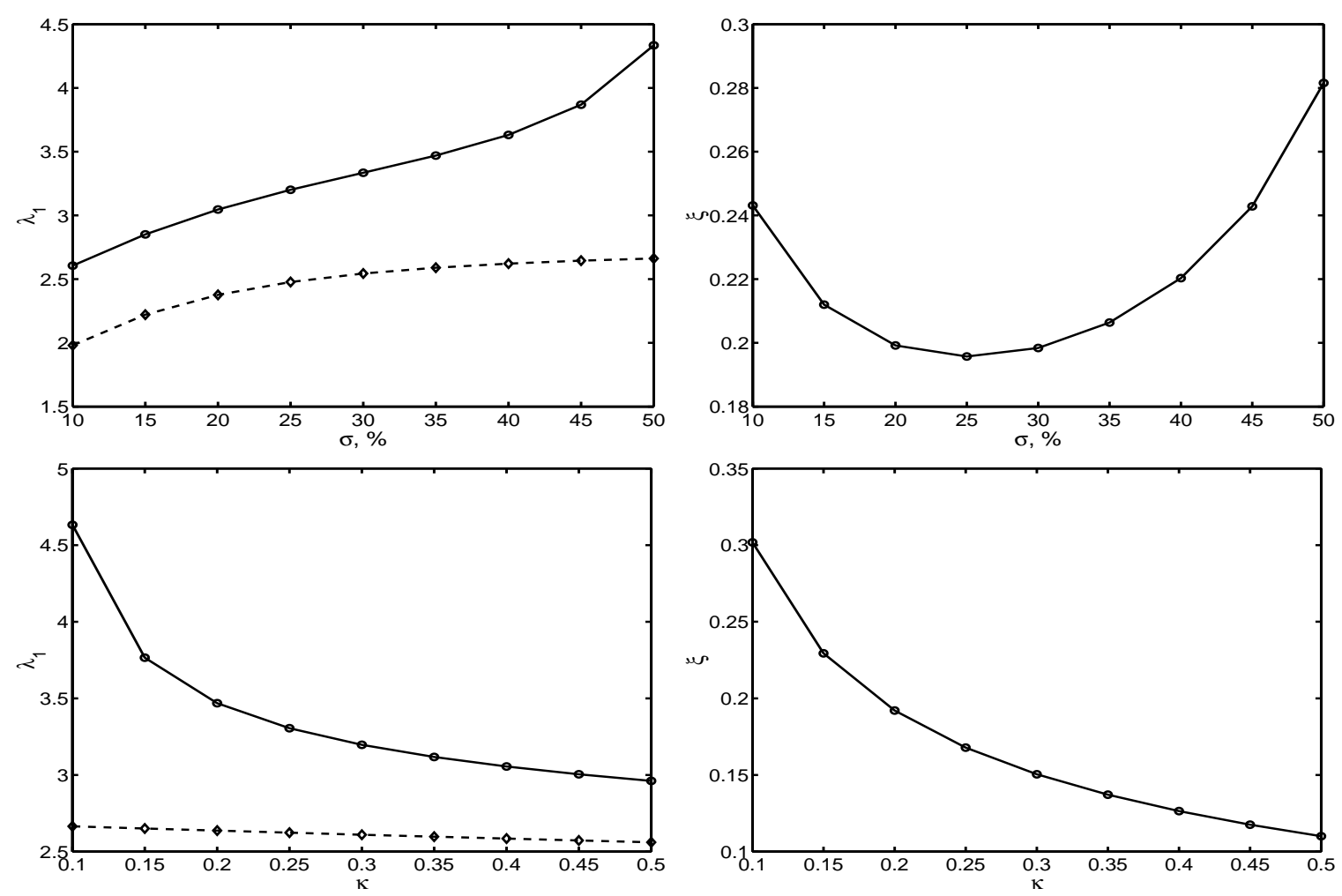

Figure 2: Impact of Production Shocks on Optimal Shipping Decisions

The left panels depict the optimal boundary at which the shipment takes place $\left(\lambda_{1}\right)$ while the right panels depict the optimal fraction of shipment $(\xi$ ), both as a function of the diffusion parameter $\sigma$ (first row) and the drift parameter $\kappa$ (second row) of the capital stock process. The circle-solid line denotes the general cost case while the diamond-dashed line denotes the purely proportional case $(\beta=0)$. Model parameters are $\kappa=0.11, \gamma=-1, \rho=0.15, \alpha=0.18, \beta=0.001$. 
seems to become more sensitive to the technology parameters $(\sigma, \kappa)$ with economies of scale in the cost structure (the solid lines) than without (the dashed lines). Overall, the optimal boundary $\lambda_{1}$ increases with the diffusion parameter $\sigma$ but decreases with the drift parameter $\kappa$. As the diffusion parameter $\sigma$ increases, one expects more variation in the capital stock and hence expects a higher chance that the capital stock comes back to balance by its own force. Given such expectations, consumers are willing to tolerate a higher imbalance (a larger $\lambda_{1}$ ) before starting shipment. On the other hand, a large positive $\kappa$ implies that the higher the capital stock, the faster it increases. Such a force will certainly drive a given imbalance to a further extent. Expecting future divergence in capital stock imbalance from a larger positive $\kappa$, consumers take actions early and begin shipping at a smaller $\lambda_{1}$.

In the purely proportional cost case of Dumas (1992), the optimal shipping quantity is infinitesimal, regardless of the production technology. In presence of economies of scale in the transportation cost, the optimal shipping quantity becomes a nontrivial decision and is sensitive to the variations in the production technology. Interestingly, as shown in the top right panel of Figure 2, the dependence of the optimal fraction of shipment, $\xi$, on the diffusion parameter $\sigma$ is not monotonic. The optimal fraction of shipment first decreases and then increases with $\sigma$. Therefore, more than one force is at work. On the one hand, when the imbalance becomes larger, one in general needs to ship more to get back to balance. Such a force predicts an increase in $\xi$ as $\sigma$ increases. On the other hand, one may expect more frequent hitting of the boundary $\lambda_{1}$ and hence more frequent intervention. One might hence reduce the shipping quantity to reduce the total cost of transportation.

In case of the drift parameter $\kappa$, the optimal shipping quantity $\xi$ declines as $\kappa$ increases. Such a decline accompanies the decline in the outer boundary $\lambda_{1}$.

\section{Consumer Preference}

Consumers discount both risk and time. Such discounting is captured, respectively, by consumers' relative risk aversion parameter $(1-\gamma)$ and their time discount parameter $\rho$. Figure 3 depicts the dependence of the optimal shipping decisions on consumers' preference along both dimensions.

Both risk aversion and time aversion increase consumers' preference for consumption smoothing and hence their desire to achieve and maintain a balanced account of capital stock. Therefore, the 

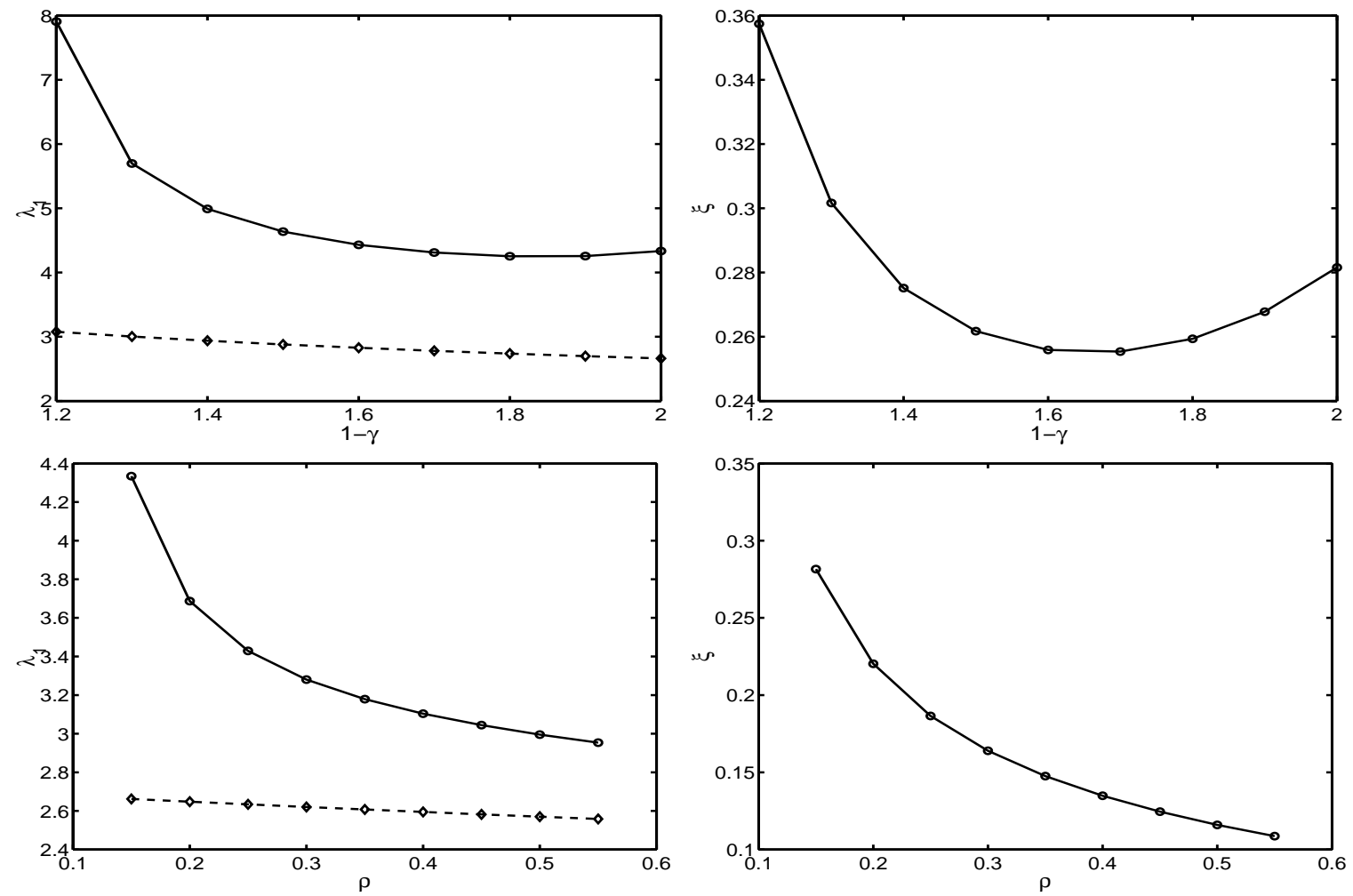

Figure 3: Impact of Consumer Preference on Optimal Shipping Decisions

The left panels depict the optimal time of trade $\left(\lambda_{1}\right)$ while the right panels depict the optimal amount of trade $(\xi)$, both as a function of the relative risk aversion $(1-\gamma)$ (first row) and the time discount factor $\rho$ (last row). The circle-solid line denotes the general case while the diamond-dashed line denotes the purely proportional case $(\beta=0)$. Model parameters are: $\kappa=0.11, \gamma=-1, \rho=0.15, \alpha=0.18, \beta=$ 0.001 . 
boundary $\lambda_{1}$ for optimal shipping decreases with increasing relative risk aversion $(1-\gamma)$ and increasing time discounting $\rho$. The optimal shipping amount normally follows the trend of $\lambda_{1}$. That is, more is shipped when the boundary is further out. This trend is reversed at high risk aversion levels. When the consumer's risk aversion is very high, the consumer not only wants to ship more frequently to maintain a narrower band $\left[\lambda_{1}, 1 / \lambda_{1}\right]$, but also wants to ship as much as possible to achieve immediate reduction in the capital stock imbalance.

To a consumer, the optimal shipping decision is determined by the trade-off between the benefit of risk diversification and the cost of intervention. The benefit of diversification drives the consumer to act more frequently and ship a larger amount to achieve a balance in capital stocks. The cost of shipment not only delays the consumer's action but also reduces the magnitude of the action. As the desire for diversification increases with increasing risk aversion, cost reduction becomes less important for the consumer. Therefore, a consumer with high relative risk aversion not only wants to intervene early at low $\lambda_{1}$, but also wants to ship a larger amount $(\xi)$ to achieve better consumption smoothing.

\section{Optimal Consumption and the Capital Imbalance Dynamics}

By Ito's lemma, the dynamic process for the physical imbalance of the capital stock, $\omega$, can be derived from the bivariate process in (1),

$$
d \omega=\left[-\frac{c}{K}+\frac{c^{*}}{K^{*}}\right] d t+\sqrt{2} \sigma d z^{\prime}
$$

where $d z^{\prime}=\left(d z-d z^{*}\right) / \sqrt{2}$ is a standardized white noise. The physical imbalance has a constant instantaneous variance of $2 \sigma^{2}$. The drift of the physical imbalance is determined by the difference in the consumption rates (the ratio of consumption to capital stock) between the two countries. Recall from (7) that the optimal consumption is determined by the marginal utility of the indirect utility function,

$$
c=V_{1}^{\frac{1}{\gamma-1}}, \quad c^{*}=V_{2}^{\frac{1}{\gamma-1}} .
$$




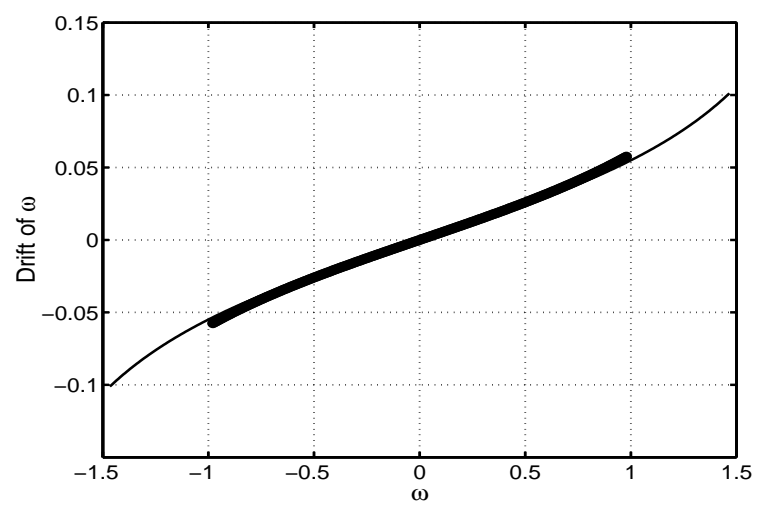

Figure 4: The drift of $\omega$ process

The solid line represents a general cost structure with economies of scale $(\beta=0.001)$. The bolded line represents the purely proportional case absent of economies of scale $(\beta=0)$. Model parameters: $\kappa=0.11, \sigma=0.5, \rho=0.15, \gamma=-1 ; \alpha=0.18$.

Apply the change of variables in (13), we have

$$
\frac{c}{K}=\left\|e^{I(-\omega)} I^{\prime}(\omega)\right\|^{\frac{1}{\gamma-1}}, \quad \frac{c^{*}}{K^{*}}=\left\|e^{I(\omega)} I^{\prime}(-\omega)\right\|^{\frac{1}{\gamma-1}}
$$

Obviously, the drift of the physical imbalance is a highly nonlinear function of the imbalance level $\omega$. In Figure 4, we solve the transformed utility function and plot the drift of $\omega$ as a function of $\omega$. For ease of comparison, we choose the same parameters as in Dumas (1992) for the purely proportional cost case: $\kappa=0.11, \sigma=0.5, \rho=0.15, \gamma=-1, \alpha=0.18$. The optimal shipping boundary is $\lambda_{1}=2.6621$ $\left(\omega_{1} \equiv \ln \lambda_{1}=0.9791\right)$. The optimal shipping amount is infinitesimal. Under our general cost structure, we set $\beta=0.001$ with otherwise the same set of parameters. The optimal shipping boundary increases to $\lambda_{1}=4.3342\left(\omega_{1}=1.4665\right)$ and the optimal shipping amount is $\xi=28.16 \%$ of the imbalance $K-K^{*}$. The ex-shipping imbalance becomes $\lambda_{2}=1.9222\left(\omega_{2}=0.6535\right)$. The bolded line depicts the same divergent feature of the drift function as in Dumas (1992)'s purely proportional case. In the presence of economies of scale, the feature is similar except that the shipping boundary is pushed further out. This divergent feature says that the drift is positive when $\omega$ is positive and vice versa. As a result, the imbalance is constantly driven to one of the boundaries. Such a divergent feature is a result of 

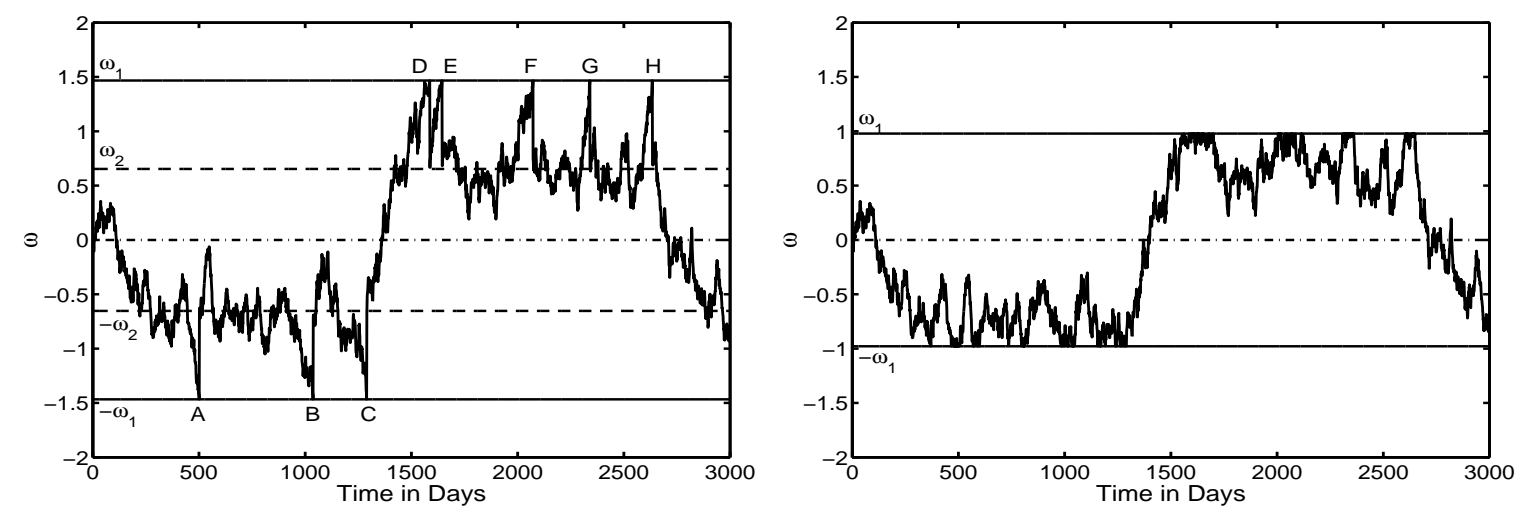

Figure 5: The Physical Imbalance Dynamics of Capital Stock, $\omega$

The processes are simulated based on the model parameters: $\kappa=0.11, \sigma=0.5, \rho=0.15, \gamma=-1 ; \alpha=$ 0.18 . The coefficient of economies $\beta$ is set to 0.001 for the left panel and zero for the right panel. The solid lines at $\omega_{1}$ and $-\omega_{1}$ depict the boundaries at which it is optimal to ship. The two dashed lines at $\omega_{2}$ and $-\omega_{2}$ depict the ex-shipment imbalance. The solid and dashed lines overlap in absence of economies of scale (right panel). The dash-dotted line in the middle $(\omega=0)$ denotes the benchmark of exact capital balance. The points marked $A, B, C, D, E, F, G, H$ in the left panel denote points where finite shipment occurs.

consumption smoothing. The imbalance in optimal consumption is less than the imbalance in capital stock between the two countries:

$$
\begin{aligned}
& \frac{c}{c^{*}} \leq \frac{K}{K^{*}}, \quad \text { when } K>K^{*} \\
& \frac{c^{*}}{c} \leq \frac{K^{*}}{K}, \quad \text { when } K^{*}>K .
\end{aligned}
$$

While the drift functions for cases with and without economies of scale look qualitatively the same, the dynamics of physical imbalance for the capital stock differs sharply because of the different decisions on optimal shipping quantity. In Figure 5, we present a simulated series of the physical imbalance $\omega$ with (left panel) and without economies of scale (right panel), based on otherwise identical model parameters. Compared to the purely proportional case (right panel), the addition of modest economies of scale (left panel) pushes the optimal shipping boundary $\left[\omega_{1},-\omega_{1}\right]$ further out due to the higher total cost. More importantly, the presence of economies of scale induces finite jumps in the physical imbalance process. Whenever either of the two optimal shipping boundaries (the two solid lines at $\omega_{1}$ and $\left.-\omega_{1}\right)$ is reached, it is optimal to ship a finite percentage $\xi=28.16 \%$ so that the imbalance jumps 
inside the band. The ex-shipment boundaries are captured by the two dashed lines at $\omega_{2}$ and $-\omega_{2}$. The points marked $A, B, C, D, E, F, G, H$ in the left panel highlight the jumps in the imbalance process. In contrast, in absence of economies of scale in the cost structure (right panel), there are no jumps in the imbalance process. Whenever the boundary of $\omega_{1}$ or $-\omega_{1}$ is reached, the physical imbalance is pushed back by an infinitesimal amount. This infinitesimal shipping, together with the divergent feature of the drift function, dictates that the physical imbalance stays at the boundary most of the time.

\section{The Dynamic Behavior of Real Exchange Rates}

Let $p$ denote the price of goods located at home relative to goods located abroad (the price of a unit of $K$ in units of $K^{*}$ ). It is given by the ratio of the marginal utilities:

$$
p=\frac{V_{1}\left(K, K^{*}\right)}{V_{2}\left(K, K^{*}\right)}
$$

Because of the homogeneity of $V$, the relative price $p$ is a function of $\omega$ only:

$$
p(\omega)=e^{-\omega} \frac{I^{\prime}(\omega)}{I^{\prime}(-\omega)}
$$

The Law of One Price (LOP) prevails when $p=1$. Let $x(\omega) \equiv \ln p(\omega)$ denote the log real exchange rate. It is given by

$$
x(\omega) \equiv \ln p(\omega)=-\omega+\ln I^{\prime}(\omega) / I^{\prime}(-\omega)
$$

Figure 6 depicts the log real exchange rate, $x(\omega)$, as a function of the physical imbalance $\omega$. We compare the purely proportional case (bolded line) with the general case with economies of scale (solid line). The model parameters are the same as in Dumas (1992) except $\beta=0.001$ for the general cost structure case.

In the presence of economies of scale in the shipping cost, the mapping from the real exchange rate to the physical imbalance is no longer unique. In particular, the marginal utilities are the same at the two boundaries $\omega_{1}$ and $\omega_{2}$ (and at also their negative counterparts) by virtue of smooth pasting. Thus, the real exchange rates are also the same at these two boundaries. The maximum deviation from 


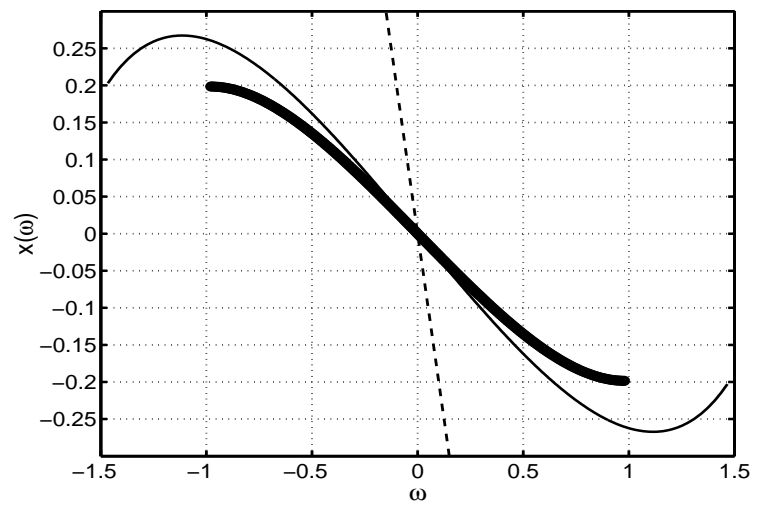

Figure 6: The Logarithm of the Real Exchange Rate

Lines depict the logarithm of the real exchange rate $x(\omega) \equiv \ln p(\omega)$ as a function of the physical imbalance of capital stock. The model parameters are $\kappa=0.11, \sigma=0.5, \rho=0.15, \gamma=-1 ; \alpha=0.18$. The coefficient of economies of scale is set to $\beta=0.001$ for the solid line and to zero for the bolded line. The dash-dotted line represents the autarky case with $x(\omega)=(\gamma-1) \omega$.

purchasing power parity does not occur at the outer boundary of physical imbalance at which shipping occurs, nor does it occur at the ex-shipping boundary. Instead, the maximum is achieved between the two boundaries.

The impact of such smooth pasting is analogous to the "honeymoon effect" described in Krugman (1991). As the physical imbalance increases, the deviation from the parity increases. However, as the imbalance is near the outer boundary of $\omega_{1}$, consumers realize that the shipping of the capital stock is imminent. In anticipation of the shipment, the real exchange rate reverses direction and the deviation from the parity starts to decrease before reaching the boundary. Once the boundary is reached, a finite amount of capital stock is shipped from one country to the other; yet, no arbitrage dictates that the marginal utilities and hence the real exchange rate before and after the shipment are exactly the same. Thus, there are no jumps in the real exchange rates although there are jumps in the physical imbalance of the capital stock.

As the real exchange rate is a direct function of the physical imbalance of the capital stock, we can regard the physical imbalance $\omega$ as the state variable representing the underlying economy. Given the dynamics of the state variable, we can determine the dynamics of the real exchange rate. Nevertheless, due to the absence of one-to-one correspondence between the two, we cannot uniquely determine the 

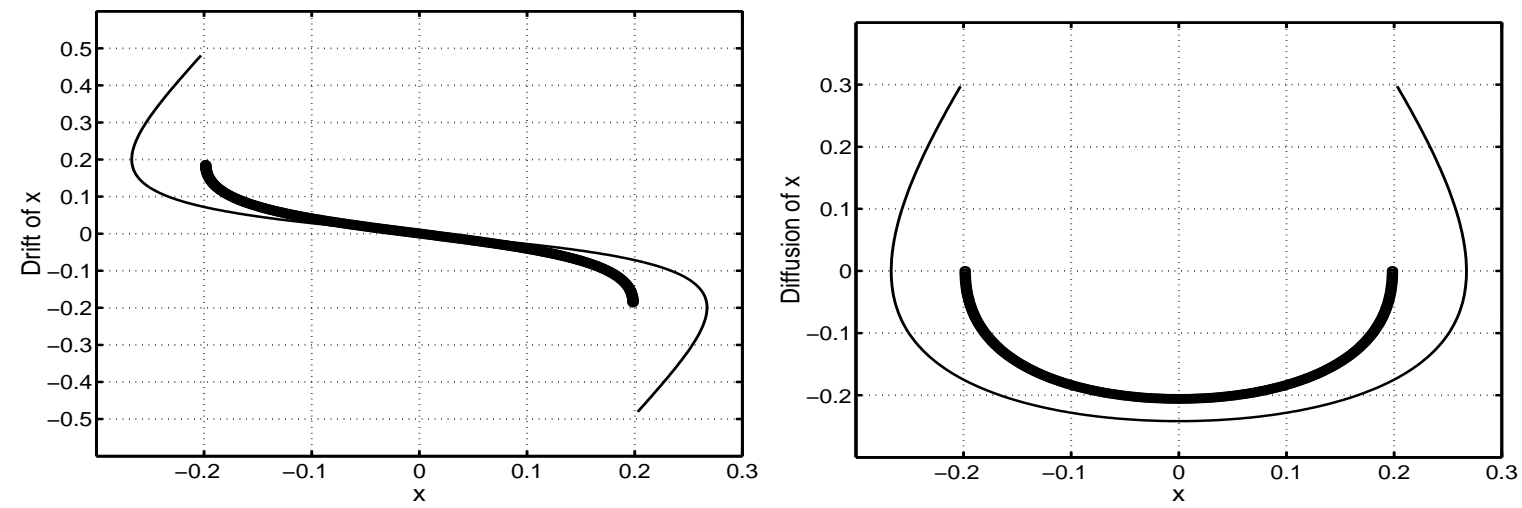

Figure 7: The Drift and Diffusion of the Log Real Exchange Rate $x(\omega)$

Lines depict the drift (left panel) and diffusion (right panel) of the log real exchange rate $x(\omega)$. The model parameters are: $\kappa=0.11, \sigma=0.5, \rho=0.15, \gamma=-1 ; \alpha=0.18$. The coefficient of economies of scale $\beta$ is set to 0.001 for the solid line and zero for the bolded line.

state variable $\omega$ from the real exchange rate process. For example, at $x=-0.2028$, the state variable can either be at $\omega_{1}=1.4665$ or at $\omega_{2}=0.6536$.

This absence of one-to-one correspondence between the real exchange rate and the state variable has important implications for the exchange rate dynamics. In Figure 7, we depict the drift and diffusion functions of the log real exchange rate, $x(\omega)$. Again, we compare the case with economies of scale (solid line) and the case without economies of scale (bolded line). We find that, holding everything else constant, incorporating a modest amount of economies of scale not only reduces the reverting speed to parity (the drift function is much flatter), but also increases the overall volatility level of the deviation (the diffusion function takes larger values).

What is most distinctive, however, is that, in the presence of the economies of scale, neither the drift nor the diffusion is completely determined by the current value of the exchange rate. For example, at $x=-0.2028$, the drift of $x$ can either by 0.4806 or 0.0739 . Similarly, the diffusion can either be 0.2974 or -0.1724 . As the sign of the diffusion indicates the different directions of the impact of a production shock, the two values say that the same shock can either move the exchange rate positively or negatively.

Such indeterminacies have important implications for empirical studies. Time series analysis of the real exchange rate by itself is no longer capable of revealing the full information about the exchange 

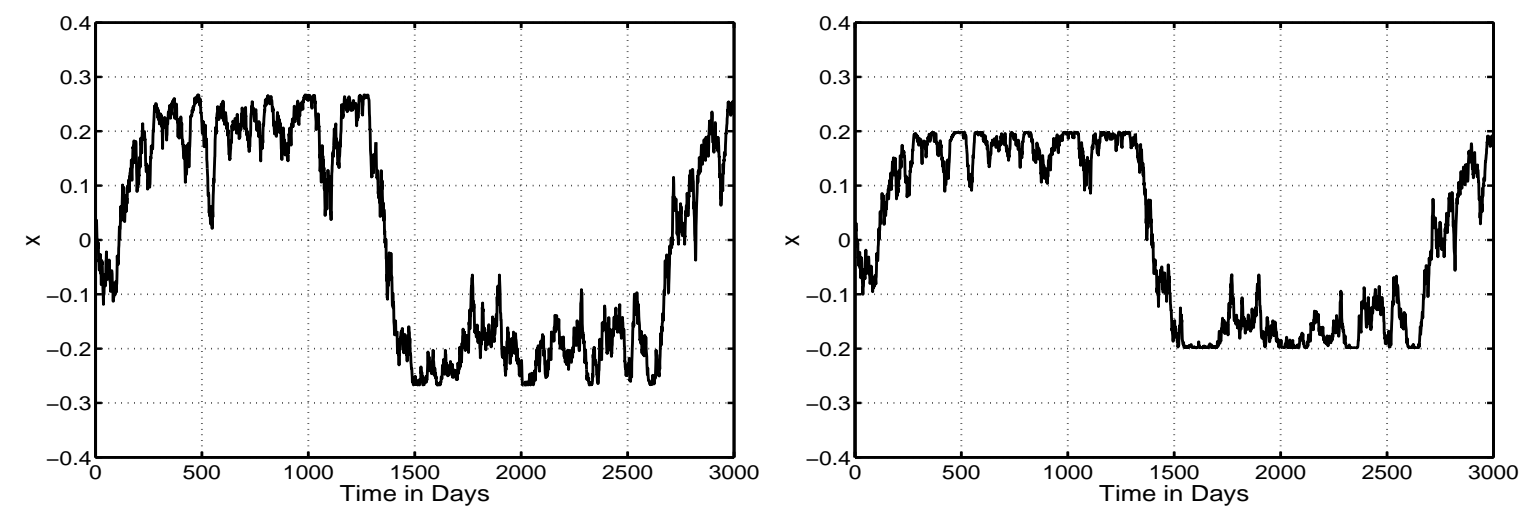

Figure 8: The Simulated Process of Real Exchange Rate, $x$

Model parameters are: $\kappa=0.11, \sigma=0.5, \rho=0.15, \gamma=-1 ; \alpha=0.18$. $\beta$ is set to 0.001 for the left panel and zero for the right panel.

rate dynamics. A more informative analysis may also need to include economic fundamentals that proxy for capital imbalance, such as trade deficit or capital flows. Dumas (1992) argues that a linear specification in estimating the real exchange rate dynamics is severely misspecified and hence may lead to erroneous conclusions. His modeling effort has motivated several empirical studies to explore nonlinear specifications in testing the mean-reverting behavior of the real exchange rate. Our more realistic specification in the cost structure of goods transportation further indicates that a simple exogenous time series analysis of the real exchange rate may still lead to erroneous conclusions even if one considers nonlinearity and/or heteroskedasticity. The key issue is that the drift and diffusion functions of the real exchange rate are not completely determined by the real exchange rate levels. Our model argues for joint analysis of real exchange rates and economic fundamentals.

Another important observation from Figure 7 is that under the purely proportional cost case of Dumas (1992), the instantaneous volatility of the real exchange rate is maximal at parity $x=0$. The instantaneous variance approaches zero monotonically as the deviation from parity increases and approaches its boundary. In contrast, in the presence of economies of scale, the maximum instantaneous variance does not occur at parity, nor does it happen at the maximum boundary, but at an intermediate level of deviation from parity. These differences transform directly to different behaviors in the exchange rate dynamics. 
In Figure 8, we plot the simulated dynamics of the real exchange rate with (left panel) and without (right panel) economies of scale. The dynamics are derived from the simulated dynamics of the state variable $\omega$ in Figure 5. As expected, in the presence of economies of scale (left panel), the allowable band of deviation from parity is larger. But more importantly, in absence of economies of scale, the real exchange rate dwells at the boundary with small local variation. In contrast, in the presence of economies of scale, the real exchange rate rarely dwells at the boundary, but nevertheless persistently stays away from parity. Furthermore, the deviations have much larger volatilities than the purely proportional cost case.

\section{Concluding Remarks}

This article constructs a dynamic general equilibrium model of real exchange rates allowing economies of scale in the cost structure for goods transportation. Compared to the earlier literature focusing on purely proportional cost, our paper represents a significant theoretical breakthrough. We propose an efficient procedure to simultaneously solve both the optimal shipping time and the optimal shipping quantity. Given the solution, we analyze the impact of the cost structure on the optimal shipping decision and on the equilibrium behavior of the real exchange rate dynamics. We find that our general cost structure generates more realistic real exchange rate behavior. We also find that, in the presence of economies of scale in the cost structure, one can no longer fully identify the real exchange rate dynamics from the exchange rate data alone. A more informative analysis should also include economic fundamentals.

An important direction for future research is to apply the model to guide future empirical studies. In particular, our model illustrates the danger of drawing premature conclusions from exogenous time series analysis based on exchange rate data alone. On the other hand, directly calibrating our model to the exchange rate and economic fundamentals, should reveal important information on the real exchange rate dynamics, increase our understanding of the production technology, the consumer preference, and the cost structure in international trade, as well as their impact on, and links to, the real exchange rate behavior. 


\section{Appendix A. Maximum Shipment}

Lemma 1 Irrespective of the cost structure, consumers never have the incentive to transfer more than the stock imbalance: $X_{\max }=\left|K-K^{*}\right|$.

When the cost of goods transportation does not depend upon the amount of shipment, consumers have the incentive to transfer the maximal amount to achieve immediate stock balance. Let $X_{\max }$ denote this maximal amount of the shipment when the total cost of transportation does not depend on the shipment. Let $C$ denote this total cost. Assume that the home country has a larger capital stock than the foreign country, $K>K^{*}$, and decides to ship $X_{\max }$ to the foreign country. We have

$$
K-X_{\max }=K^{*}+X_{\max }-C .
$$

That is, stock balance is achieved after the shipment. The equality in (A1) yields

$$
X_{\max }=\frac{K-K^{*}+C}{2}
$$

which says that the amount of transfer increases with the total $\operatorname{cost} C$.

However, for the shipment to be optimal, the total $\operatorname{cost} C$ cannot be too high. In particular, consumers in the foreign country have the incentive to receive a shipment only when they can gain from it. Thus, for any transfer to be in effect, we need $X_{\max }-C>0$. Consumers in the foreign country can simply refuse to pick up the package if the cost of picking up the package is more expensive than the value of the package.

Therefore, the maximum possible shipment is achieved at the maximum possible total $\operatorname{cost} C_{\max }=X_{\max }$. Plug this maximum cost into (A2), we obtain

$$
X_{\max }=K-K^{*},
$$

which represents the maximum possible amount of shipment in any cost structure.

When the foreign country has a larger capital stock, $K^{*}>K$, and decides to ship some of the stock to the home country, similar argument yields $X_{\max }=K^{*}-K$. Thus, in all cases, the maximum shipment is given by

$$
X_{\max }=\left|K-K^{*}\right| .
$$

All through the paper, we only consider the case of $K>K *$ and determine the case of $K^{*}>K$ via symmetry. 


\section{Appendix B. Optimal Shipping}

Apply the change of variables to the first order condition in (12), we have

$$
e^{(\eta-1) I\left(\omega_{2}\right)}=\frac{-I^{\prime}\left(\omega_{2}\right)\left(1+(1-\alpha) \lambda_{2}\right)+(1-\alpha) \lambda_{2} \gamma}{(\eta-1)\left(T_{1}\left(\omega_{2}\right)-(1-\alpha) \lambda_{2} T_{2}\left(\omega_{2}\right)\right)}
$$

where

$$
\begin{aligned}
& T_{1}=\zeta_{1}\left(\left(I^{\prime}\right)^{2}+I^{\prime \prime}-I^{\prime}\right)+\zeta_{2}\left(-\left(I^{\prime}\right)^{2}+\gamma I^{\prime}-I^{\prime \prime}\right) \\
& T_{2}=\zeta_{1}\left(-\left(I^{\prime}\right)^{2}+\gamma I^{\prime}-I^{\prime \prime}\right)+\zeta_{2}\left(\left(I^{\prime}-\gamma\right)^{2}+I^{\prime \prime}+\left(I^{\prime}-\gamma\right)\right) .
\end{aligned}
$$

We drop the dependence of $I^{\prime}, I^{\prime \prime}, \zeta$ on $\omega_{2}$ for clarity. We can also derive an expression for $e^{(\eta-1) I\left(\omega_{2}\right)}$ from the ordinary differential equation (14):

$$
I^{\prime \prime}=-\left(I^{\prime}\right)^{2}+I^{\prime} \gamma+\frac{1}{\sigma^{2} \eta} e^{(\eta-1) I}\left[I^{\prime} \zeta_{1}+\left(\gamma-I^{\prime}\right) \zeta_{2}\right]+\delta
$$

Combine the two equations (B3) and (B4), we cancel out the $I\left(\omega_{2}\right)$ term and obtain a quadratic function of $I^{\prime \prime}\left(\omega_{2}\right)$ in terms of $I^{\prime}\left(\omega_{2}\right)$ :

$$
A\left(I^{\prime \prime}\right)^{2}+B I^{\prime \prime}+C=0
$$

where the coefficients $[A, B, C]$ are functions of $I^{\prime}\left(\omega_{2}\right)$ and model parameters. They are given by

$$
\begin{aligned}
A & =\left(\zeta_{1}-\zeta_{2}\right)\left(1+(1-\alpha) \lambda_{2}\right) \\
B & =G+E A ; \\
C & =E G-F .
\end{aligned}
$$

with

$$
\begin{aligned}
G & =I^{\prime}\left[\zeta_{1}\left(I^{\prime}-1\right)+\zeta_{2}\left(-I^{\prime}+\gamma\right)\right]-(1-\alpha) \lambda_{2}\left(I^{\prime}-\gamma\right)\left[-\zeta_{1} I^{\prime}+\zeta_{2}\left(\left(I^{\prime}-\gamma\right)+1\right)\right] \\
E & =\left(I^{\prime}\right)^{2}-I^{\prime} \gamma-\delta \\
F & =\frac{\left(I^{\prime}+(1-\alpha) \lambda_{2}\left(I^{\prime}-\gamma\right)\right)\left[-\zeta_{1} I^{\prime}+\zeta_{2}\left(I^{\prime}-\gamma\right)\right]}{\eta(\eta-1) \sigma^{2}}
\end{aligned}
$$


Given that the discrimant $B^{2}-4 A C>0$, the quadratic equation has two real roots. We choose the root that ensures convergence for the ordinary differential equation. In particular, a geometric analysis indicates that the convergent root is

$$
I^{\prime \prime}\left(\omega_{2}\right)=\frac{-B+\sqrt{B^{2}-4 A C}}{2 A} .
$$




\section{References}

Atkinson, C., and P. Wilmott, 1995, Portfolio management with transaction costs: An asymptotic analysis of the morton and pliska model, Mathematical Finance 5, 357-367.

Baum, Christopher F., John T. Barkoulas, and Mustafa Caglayan, 2001, Nonlinear adjustment to purchasing power parity in the post-bretton woods era, Journal of International Money and Finance 20, 379-399.

Constantinides, George M., 1986, Capital market equilibrium with transaction costs, Journal of Political Economy $94,842-862$.

Cuoco, Domenico, and Hong Liu, 2000, Optimal consumption of a divisible durable good, Journal of Economic Dynamics and Control 24, 561-613.

Cvitanić, Jakša, 1996, Hedging and portfolio optimization under transaction costs: A martingale approach, Mathematical Finance 6, 133-165.

Davis, M. H. A., and A. R. Norman, 1990, Portolio selection with transaction costs, Mathematics of Operations Research 15, 676-713.

Dornbusch, Rudiger, 1976, Expectations and exchange rate dynamics, Journal of Political Economy 84, 11611176.

Duffie, Darrell, and Tong-Sheng Sun, 1990, Transaction costs and portfolio choice in a discrete-continuous-timesetting, Journal of Economic Dynamics and Control 14, 35-52.

Dumas, Bernard, 1992, Dynamic equilibrium and the real exchange rate in a spatially separated world, Review of Financial Studies 5, 153-180.

Dumas, Bernard, and Elisa Luciano, 1991, An exact solution to a dynamic portfolio choice problem under transaction costs, Journal of Finance 46, 577-596.

Dumas, Bernard, and Raman Uppal, 2001, Global diversification, growth and welfare with imperfectly integrated markets for goods, Review of Financial Studies 14, 277-305.

Eastham, J., and Kevin J. Hastings, 1988, Optimal impulse control of portfolios, Mathematics of Operations Research 13, 588-605.

Froot, Kenneth, Michael Kim, and Kenneth Rogoff, 1995, The law of one price over 700 years, NBER Working Paper 5132 .

Grossman, Sanford J., and Guy Laroque, 1990, Asset pricing and optimal portfolio choice in the presence of illiquid durable assets, Econometrica 58, 25-52. 
Hollifield, Burton, and Raman Uppal, 1997, An examination of uncovered interest rate parity in segmented international commodity markets, Journal of Finance 52, 2145-2170.

Korn, Ralf, 1998, Portoflio optimization with strictly positive transaction costs and impulse control, Finance and Stochastics 2, 85-114.

Krugman, Paul R., 1991, Target zones and exchange rate dynamics, Quarterly Journal of Economics 106, 669682.

Liu, Hong, 2001, Optimal consumption and investment with transaction costs and multiple stocks, manuscript, Washington University.

Liu, Hong, and Mark Loewenstein, 2001, Optimal portfolio selection with transaction costs and finite horizons, Review of Financial Studies forthcoming.

Lo, Andrew, Harry Mamaysky, and Jiang Wang, 2000, Asset prices and trading volume under fixed transaction costs, manuscript, MIT.

Lothian, James R., and Mark P. Taylor, 1996, Real exchange rate behavior: The recent float from the perspective of the past two centuries, Journal of Political Economy 104, 488-509.

Merton, Robert C., 1971, Optimum consumption and portfolio rules in a continuous time model, Journal of Economic Theory 3, 373-413.

Michael, Panos, A. Robert Nobay, and David A. Peel, 1997, Transaction costs and nonlinear adjustment in real exchange rates: An empirical investigation, Journal of Political Economy 105, 862-879.

Morton, Andrew J., and Stanley R. Pliska, 1995, Optimal portfolio management with fixed transaction costs, Mathematical Finance 5, 337-356.

Obstfeld, Maurice, and Kenneth Rogoff, 1995, The mirage of fixed exchange rates, Journal of Economic Perspectives $9,73-96$.

Oksendal, B., and A. Sulem, 1999, Optimal consumption and portfolio with both fixed and proportional transaction costs, manuscript, University of Oslo.

Rogoff, Kenneth, 1996, The purchasing power parity puzzle, Journal of Economic Literature 34, 647-668.

Sarantis, Nicholas, 1999, Modeling non-linearities in real effective exchange rates, Journal of International Money and Finance 18, 27-45.

Schroder, Mark, 1995, Optimal portfolio selection with fixed transaction costs: Numerical solutions, manuscript, Michigan State University. 
Schroder, Mark, 1997, Optimal portfolio selection with proportional and fixed transaction costs, manuscript, Michigan State University.

Shreve, S. E., and H. M. Soner, 1994, Optimal investment and consumption with transaction costs, The Annals of Applied Probability 4, 609-692.

Taylor, Mark P., and David A. Peel, 2000, Nonlinear adjustment, long-run equilibrium ad exchange rate fundamentals, Journal of International Money and Finance 19, 33-53.

Uppal, Raman, 1993, A general equilibrium model of international portfolio choice, Journal of Finance 48, $529-553$.

Vayanos, Dimitri, 1998, Transaction costs and asset prices: A dynamic equilibrium model, Review of Financial Studies 11, 1-58. 